Research Article

\title{
Evaluation Method of Floor Heave Damage Degree and a Case Study in Zaoquan Coal Mine, China
}

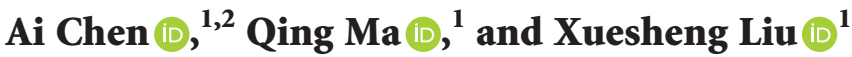 \\ ${ }^{1}$ School of Energy and Mining Engineering, Shandong University of Science and Technology, Qingdao 266590, China \\ ${ }^{2}$ Ningxia Coal Industry Co., Ltd., of China Energy Group, Yinchuan 750000, China \\ Correspondence should be addressed to Qing Ma; 15764250774@163.com and Xuesheng Liu; xuesheng1134@163.com
}

Received 10 July 2021; Revised 29 July 2021; Accepted 11 August 2021; Published 20 August 2021

Academic Editor: Gan Feng

Copyright $(2021$ Ai Chen et al. This is an open access article distributed under the Creative Commons Attribution License, which permits unrestricted use, distribution, and reproduction in any medium, provided the original work is properly cited.

With the continuous increase of mining depth and complex mining geological conditions, the mileage of roadways in underground engineering such as coal mine is increasing year by year. Complex conditions lead to different floor heave failure laws, and the control technology and strategy should be changed accordingly. How to evaluate the damage degree of floor heave under different conditions has become an urgent problem. Firstly, this paper makes a statistical analysis on the main evaluation indexes of the damage degree of roadway floor heave. Then, the fuzzy comprehensive clustering method is used to establish the classification method of floor heave damage degree, taking the floor heave amount, floor rock fragmentation degree, coal pillar size, buried depth, and floor lithology as evaluation indexes. The damage degree of floor heave can be divided into five types: light type, obvious type, severe type, destructive type, and extremely severe type. Finally, the rationality and accuracy of the method are verified by the measured value and evaluation value of No. 130203 roadway in the Zaoquan coal mine. The results can provide reference for the evaluation of the damage degree of the floor rock in similar condition mine and provide guidance for the design of the support and stability control of the failure of the roadway floor heave.

\section{Introduction}

It is generally believed that if the nineteenth century is the era of the development of long bridges and the twentieth century is the era of the development of high-rise buildings, then the twenty-first century will be the era of the development of long tunnels and the development and utilization of underground space [1-3]. As the "throat" and "basic passage" into the underground space, the damage degree of surrounding rock is very important for the safety construction of underground engineering [4]. At present, the determination method of roadway floor heave degree and surrounding rock structure mostly adopts the method of classification and evaluation of roadway floor heave stability. After judging the stability category of roadway floor heave, the support form, support parameters, and construction method of roadway are determined for selection [5-7]. The existing classification of roadway floor heave is very statistical and fuzzy, and there are many classification methods, but most of them are difficult to quantify, or the factors are too single, and the applicability is low.

On the one hand, the damage degree of roadway floor rock reflects the support effect of roadway; on the other hand, it also reflects the bearing capacity of roadway surrounding rock itself. Due to the complexity of geological characteristics, the engineering analogy method is often used in the design of rock mass stability control, which is mainly based on the support parameters under similar engineering geological conditions [8-10]. In the existing engineering analogy support design methods, the degree of rock fragmentation is mostly described by the method of stability classification of rock mass, and the support parameters are given by experience. The stability evaluation of roadway surrounding rock is a powerful tool for the existing support quality, and the next step to strengthen the support. It is a very important part of the roadway surrounding rock control design. At home and abroad, the research on the classification method of roadway surrounding rock started 
earlier, and there are many classification methods. Foreign countries began in the 1940s, such as the U.S. Terzaghi classification method. The rock mass quality classification in 1960s is represented by the rock quality index (RQD) classification of the United States. Most of these classification methods focus on the qualitative or quantitative classification of the single index [11-14]. Since the 1970s, rock mass classification has gradually developed from the single factor to multifactor, qualitative to quantitative. The representative ones are Barton's $Q$ system classification and Bieniawski's RMR classification [15, 16]. With the development of underground engineering in China, many achievements have been made in the classification of surrounding rock stability of roadway in China. In addition, some scholars have studied the influence of groundwater, in situ stress, rock integrity, and rock strength on the damage degree of surrounding rock. For example, Zhang et al. [17] studied the potential failure mode of surrounding rock based on in situ stress level evaluation, which is more suitable for deep high-stress underground engineering and makes it more convenient for field engineers to understand and apply. Luo et al. [18] studied the influence of water on the mechanical behavior of surrounding rock of the hard rock tunnel through the laboratory test. It was found that water changed the mesoscopic mechanism of spalling, reduced residual elastic strain energy, avoided over concentration of strain energy, and improved the rock burst resistance. $\mathrm{Li}$ et al. [19] used the model test and numerical simulation method to study the damage and failure law of surrounding rock of the straight wall arch tunnel under the action of principal stress in different directions. Zhao et al. [20] studied the influence of the surrounding rock structure on roadway failure degree. Through the above analysis, it can be found that there are many reasons for the deformation and failure of roadway surrounding rock. Under different geological structure conditions and engineering geological conditions, the deformation and failure of surrounding rock are different. Therefore, the main controlling factors of roadway surrounding rock deformation are changing with the geological conditions. The deformation and failure of roadway surrounding rock are affected by many factors, such as uniaxial compressive strength of rock, rock structure, groundwater, geological structure, and in situ stress [21-25]. Therefore, it is very important to consider a variety of factors and quantitatively evaluate the degree of floor heave damage, analyze and evaluate the stability of roadway surrounding rock, establish reasonable support types and construction parameters, and provide reference for roadway construction.

Therefore, this paper first investigates and analyzes the main evaluation indexes and influencing factors of floor heave damage degree of various kinds of roadways at home and abroad. On this basis, a method of evaluation and classification of floor heave damage degree based on the fuzzy comprehensive clustering method is proposed. Finally, No. 130203 roadway in the Zaoquan coal mine is taken as an example to verify the rationality and accuracy of the method. The results can provide guidance for surrounding rock support design and stability control.

\section{Main Evaluation Indexes of Floor Heave Damage Degree of Roadway}

In order to reasonably evaluate the damage degree of floor heave, we should first have a systematic understanding of the existing main evaluation indexes and their influencing factors. Therefore, this paper randomly investigates the underground tunnels such as coal mines, subway tunnels, and other underground tunnels at home and abroad. A total of 40 main subway tunnels and 20 coal mines roadways are investigated, and the main indexes of the damage degree of the floor heave are calculated. It mainly includes two categories: (1) the amount of floor heave; (2) broken degree of floor rock. These two types are the direct indexes to evaluate the damage degree of floor heave. After the roadway is excavated, the floor rock is damaged and the floor heave is the most intuitive expression of the deformation and failure degree of the floor. In [26], the damage degree of floor heave was classified according to the amount of floor heave. This index is defined as $D$ in this paper.

(1) Light floor heave $(100-200 \mathrm{~mm})$ : the floor heave is slow and needs only a little maintenance.

(2) Obvious floor heave $(200-300 \mathrm{~mm})$ : the floor rock changes obviously and needs timely maintenance and treatment.

(3) Severe floor heave $(300-500 \mathrm{~mm})$ : the floor heave develops rapidly and lasts for a long time, which seriously threatens the transportation safety and must be expanded, renovated, and maintained.

(4) Destructive floor heave $(500-700 \mathrm{~mm})$ : the floor heave of roadway is large, which is destructive to the floor, two sides, and roof surrounding rock. The roadway can only be used after stopping production, bottoming, and renovation.

(5) Extremely severe floor heave (700 $\mathrm{mm}$ and above): the amount of floor heave is very large, the roadway is damaged seriously, and the loss of roadway section is more than $1 / 5$, so it can be used only after many renovations.

The broken degree of floor rock is generally measured by ultrasonic wave velocity. The change of wave velocity reflects the failure degree of floor rock. Generally speaking, the smaller the wave velocity is, the lower the integrity of surrounding rock is and the higher the damage degree of floor heave is. The higher the wave velocity is, the higher the integrity of surrounding rock is and the lower the damage degree of floor heave is. The damage degree of floor heave corresponding to different acoustic wave velocities is shown in Table 1 [7].

The field investigation results and the comparison of previous literature further verify that the damage degree of floor heave is divided only according to the amount of floor heave and the degree of floor rock fragmentation. It is difficult to effectively guide the design of floor heave support and control, and there is a lack of extensive field engineering guidance. When evaluating the damage degree of floor heave, we need to consider the main factors that affect the 
TABLE 1: Damage degree of floor heave corresponding to different acoustic wave velocities [7].

\begin{tabular}{lccccc}
\hline Wave velocity of surrounding rock $V\left(\mathrm{~m} \cdot \mathrm{s}^{-1}\right)$ & $0 \sim 2000$ & $2000 \sim 2500$ & $2500 \sim 4000$ & $4000 \sim 5000$ & $5000 \sim 7500$ \\
\hline Qualitative description of floor rock & Extremely broken & Very broken & Severe broken & Relatively complete & Very complete \\
\hline
\end{tabular}

damage degree of floor heave and establish a more comprehensive classification system. It can provide reference for the design of floor heave support and the stability control of surrounding rock. Therefore, in the field investigation, the main influencing factors of floor heave damage degree are counted, including coal pillar size $(P)$, buried depth $(B)$, floor lithology $(Y)$, and other factors, which are indirect indicators to evaluate floor heave damage degree.

(3) Coal pillar size $(P)$ : due to the strata and surface movement caused by mining, the roadways and ground buildings in the affected area are damaged to varying degrees. In order to protect some important buildings, it is necessary to reserve protective coal pillars. The roadway is the throat of the working face, and the roadway support directly affects the normal production and safety management of the working face. At present, it is still the main method for many coal mines to set up coal pillars to protect the roadway. Reasonable width of coal pillar is the primary premise to ensure the stability of surrounding rock of roadway, and it is also one of the important contents of the roadway support design. The deformation of surrounding rock, especially floor heave, is closely related to the size of the coal pillar. The paper $[27,28]$ has an impact on the amount of floor heave in roadway and classified the damage degree of floor heave. The results are shown in Table 2.

(4) Buried depth $(B)$ : generally speaking, the greater the buried depth, the greater the Earth stress. In situ stress is the most important external factor to induce the deformation and failure of roadway and the stability of surrounding rock. Geostress is composed of gravity stress and tectonic stress. It is produced by the Earth movement and exists in the strata. It is also called initial stress. The high initial stress is affected by regional geological structure, tunnel buried depth, valley topography, and rock strength. When excavating underground cavern in the high geostress area, a series of disasters will occur in surrounding rock. In the code, the in situ stress is expressed by the ratio of rock compressive strength $R_{\mathrm{C}}$ to the maximum initial stress $\sigma_{\max }$ in the direction perpendicular to the tunnel axis. The evaluation criteria of the in situ stress level proposed by Zhang et al. [17] are shown in Table 3 .

(5) Floor lithology $(Y)$ : when the bottom plate is of different lithology, the rock strength of the bottom plate is different, and the bottom drum quantity is different. Therefore, the influence of floor lithology on floor heave can be determined by the strength of floor rock. For hard rock roadway, the strength of surrounding rock is high, and the damage degree and scope of floor rock are small after roadway excavation. In the case of no support, the selfsupporting capacity of floor rock is still at a high level, and the floor heave is relatively small. For the soft rock roadway, the stress of surrounding rock is much greater than the strength of floor rock after excavation. The floor rock is seriously damaged and has a large range, the strength is greatly reduced, and the floor heave is naturally increased. Saturated uniaxial compressive strength, as an important index to evaluate the strength of floor rock block, refers to the value of uniaxial compressive strength measured under the condition of saturated water absorption. The strength of floor rock mass is different from that of floor rock block, so it is difficult to accurately test. Therefore, the strength of floor rock block and the integrity degree of floor rock mass are often used to comprehensively reflect the stability of floor rock at all levels and the strength of floor rock mass. See Table 4 for details [29].

The saturated uniaxial compressive strength $R_{C}$ in Table 4 is the measured value, but when the measured value is missing, the rock point load strength index is 50 , which can be used for conversion:

$$
R_{c}=22.82 I_{s(50)} .
$$

The investigated coal mines and subway tunnels include both foreign mines, subway tunnels, state-owned large and medium-sized mines, and subway tunnels, as well as local small mines and subway tunnels. It includes not only the shallow mine and subway tunnel but also the deep mine and subway tunnel. The investigated roadways include not only long-term maintenance chambers such as subway tunnels, underground car yards of coal mines, and substations but also short-term service chambers or roadways such as mining roadways and connecting roadways. It is widely representative.

To sum up, this paper selects the amount of floor heave $(D)$, broken degree of floor rock $(V)$, coal pillar size $(P)$, buried depth $(B)$, and floor lithology $(Y)$ as evaluation indexes. Taking into account the classification standards, specifications, and related literature of floor heave damage degree at home and abroad, the damage degree of floor heave is divided into five grades $\mathrm{I}-\mathrm{V}$ by the single factor method. The measured values of each evaluation index are shown in Table 5.

\section{Classification Method of Floor Heave Damage Degree Based on Fuzzy Comprehensive Clustering Method}

\subsection{Principle of Fuzzy Comprehensive Clustering Method.} Fuzzy comprehensive clustering method is a comprehensive evaluation method based on fuzzy mathematics. According to the membership degree theory of fuzzy mathematics, the qualitative evaluation is transformed into quantitative evaluation, that is, the fuzzy mathematics is used to make an overall evaluation of the things or objects restricted by many factors $[30,31]$. The degree of floor heave damage is directly reflected in the amount of floor heave and the degree of floor 
TABle 2: Classification of influence of coal pillar size on floor heave of roadway [27, 28].

\begin{tabular}{lccccc}
\hline Coal pillar size $P(\mathrm{~m})$ & $0 \sim 3$ & $3 \sim 5$ & $5 \sim 7$ & $7 \sim 9$ & $9 \sim 11$ \\
\hline Floor heave $(\mathrm{mm})$ & $200 \sim 300$ & $300 \sim 400$ & $400 \sim 500$ & $>580$ & $<400$ \\
\hline
\end{tabular}

TABLE 3: Evaluation standard for the ground stress level of underground engineering [17].

\begin{tabular}{|c|c|c|c|c|}
\hline Geostress level & High ground stress problem & $\begin{array}{c}\text { Rock burst strata } \\
\text { Potential rock burst index } \Omega\end{array}$ & $\begin{array}{l}\text { Compressional strata } \\
\text { Stress evaluation index }\end{array}$ & $\begin{array}{c}\text { General strata } \\
R_{c}\left(\sigma_{\max }\right) \\
\end{array}$ \\
\hline Low to medium & $\begin{array}{l}\text { Nothing } \\
\text { Slight } \\
\text { Secondary } \\
\end{array}$ & $\begin{array}{c}<<0.4 \\
0.4 \sim 1.05 \\
1.05 \sim 2.5 \\
\end{array}$ & $\begin{array}{c}>1 \\
1 \sim 0.63 \\
0.63 \sim 0.45 \\
\end{array}$ & $\begin{array}{c}>7 \\
4 \sim 7\end{array}$ \\
\hline High & Severe & $>2.5$ & $0.45 \sim 0.32$ & $<4$ \\
\hline
\end{tabular}

TABLE 4: Relationship between saturated uniaxial compressive strength $R_{\mathrm{C}}$ and rock hardness.

\begin{tabular}{|c|c|c|c|c|c|}
\hline$R_{\mathrm{c}} / \mathrm{MPa}$ & Less than 5 & $5-15$ & $15-30$ & $30-60$ & More than 60 \\
\hline Description of hardness & Very soft rock & Soft rock & Relatively soft rock & Relatively hard rock & Very hard rock \\
\hline
\end{tabular}

TABLE 5: Grading judgment table of each index of floor heave damage degree.

\begin{tabular}{|c|c|c|c|c|c|c|}
\hline \multirow[b]{2}{*}{ Inde } & & \multicolumn{5}{|c|}{ Classification of floor heave } \\
\hline & & $\begin{array}{l}\text { Light type } \\
\text { I }\end{array}$ & $\begin{array}{l}\text { Obvious type } \\
\text { II }\end{array}$ & $\begin{array}{l}\text { Severe type } \\
\text { III }\end{array}$ & $\begin{array}{c}\text { Destructive type } \\
\text { IV }\end{array}$ & $\begin{array}{c}\text { Extremely severe type } \\
\text { V }\end{array}$ \\
\hline Direct index & $\begin{array}{c}D(\%) \\
V\left(\mathrm{~m} \cdot \mathrm{s}^{-1}\right)\end{array}$ & $\begin{array}{l}100 \sim 200 \\
0 \sim 2000\end{array}$ & $\begin{array}{c}200 \sim 300 \\
2000 \sim 2500\end{array}$ & $\begin{array}{c}300 \sim 500 \\
2500 \sim 4000\end{array}$ & $\begin{array}{c}500 \sim 700 \\
4000 \sim 5000\end{array}$ & $\begin{array}{c}>700 \\
5000 \sim 7500\end{array}$ \\
\hline Indirect index & $\begin{array}{c}P(\mathrm{~m}) \\
R_{c}\left(\sigma_{\max }\right) \\
R_{c}(\mathrm{MPa})\end{array}$ & $\begin{array}{c}0 \sim 3 \\
<4 \\
1 \sim 5 \\
\end{array}$ & $\begin{array}{l}3 \sim 5 \\
5 \sim 15\end{array}$ & $\begin{array}{c}5 \sim 7 \\
4 \sim 7 \\
15 \sim 30 \\
\end{array}$ & $\begin{array}{c}7 \sim 9 \\
30 \sim 60 \\
\end{array}$ & $\begin{array}{c}911 \\
>7 \\
>60\end{array}$ \\
\hline
\end{tabular}

rock fragmentation, and its damage is affected by many factors such as coal pillar size, buried depth, and floor lithology. The fuzzy comprehensive clustering method considers many factors and can give quantitative evaluation. The basic idea of using the fuzzy comprehensive clustering method to evaluate the damage degree of roadway floor heave is to replace "belong to" or "not belong to" with "belong to." That is to say, the degree of floor heave damage to be determined belongs to a certain type of damage, and which type of damage is the largest is the damage degree of this type. First of all, it is necessary to determine the influence index $U=\left\{u_{1}, u_{2}, u_{3}, \ldots, u_{n}\right\}$ and classification grade $V=\left\{v_{1}, v_{2}, v_{3}, \ldots, v_{n}\right\}$ of roadway floor heave damage degree. And, let the weight of each influence index be assigned as fuzzy subset $A$ on $u$, denoted as weighted fuzzy set $A=\left\{\bar{W}_{1}, \bar{W}_{2}, \bar{W}_{3}, \ldots, \bar{W}_{n}\right\}$. Then, the fuzzy relation matrix $\mathbf{R}=\left(\mathbf{r}_{\mathbf{i j}}\right)_{\mathbf{n} \times \mathbf{m}}$ is obtained by solving the membership relation of each influence index to the damage degree of roadway floor heave. Then, according to equation (1), the fuzzy relation matrix and index weight are fuzzy operation and normalized. Finally, the fuzzy comprehensive evaluation result $\mathbf{B}=\left\{\mathbf{u}_{1}, \mathbf{u}_{2}, \mathbf{u}_{3}, \ldots, \mathbf{u}_{\mathrm{m}}\right\}$ is the fuzzy clustering matrix on $V$. The matrix is used to determine the type of floor heave damage:

$$
\mathbf{B}=A \cdot \mathbf{R} .
$$

3.2. Membership Function and Fuzzy Relation Matrix. Table 5 shows the classification judgment table of each index of the damage degree of the floor heave of the roadway. After determining the classification standard, according to the different characteristics and actual conditions of each index, the fuzzy set of index composition, namely, the membership function of the index, is determined. Because the dimensions of different indicators are different, in order to classify the actual data, it is necessary to deal with the indicators dimensionless. The membership function of trapezoid distribution or semitrapezoid distribution is selected to deal with different sections. The membership function can be divided into three types, namely, small, large, and intermediate, as shown in Figure 1. Each classification grade has its corresponding membership function, where $x$ is the actual value, $a_{1}$ and $a_{2}$ are the critical values of the two adjacent index grades, and the ordinate is the membership degree $\mu(x)$. The membership functions of the three types are equations (3) (5), from which the fuzzy relation matrix $\mathbf{R}$ of floor heave failure can be obtained.where $\mu_{i j}$ is the membership degree of the actual value of the $i$ index to class $j$. 


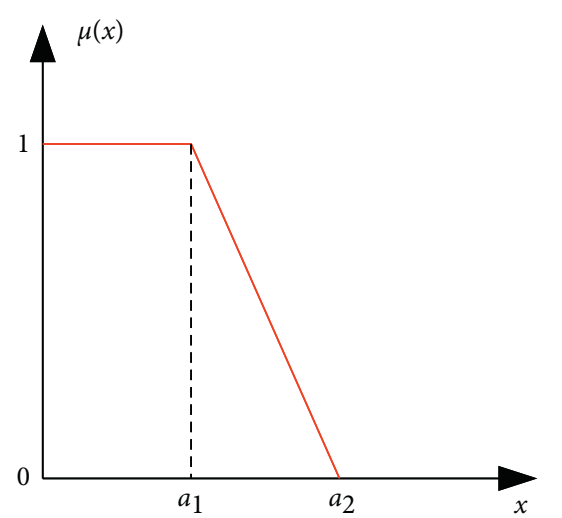

(a)

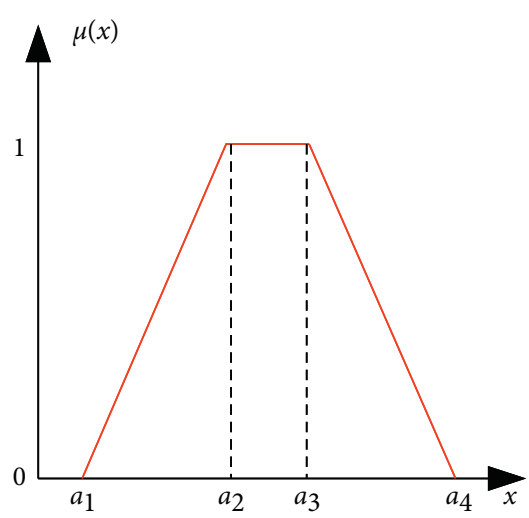

(b)

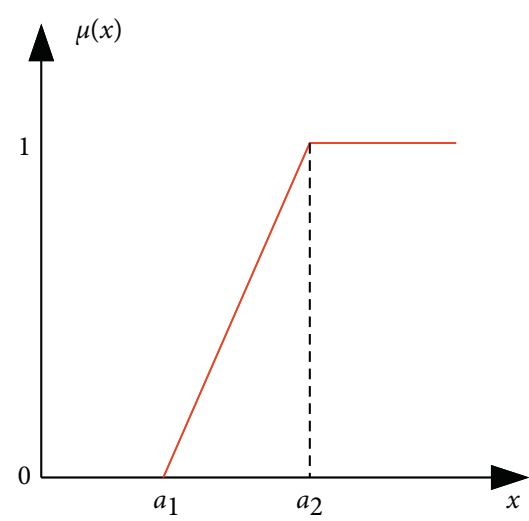

(c)

FIgURE 1: Semitrapezoid and trapezoid membership function distribution. (a) Smaller, (b) Intermediate and (c) Larger.

$$
\begin{aligned}
& \mu(x)= \begin{cases}1, & 0 \leq x \leq a_{1}, \\
\frac{a_{2}-x}{a_{2}-a_{1}}, & a_{1}<x \leq a, \\
0, & x>a_{2},\end{cases} \\
& \mu(x)= \begin{cases}0, & 0 \leq x \leq a_{1}, \\
\frac{x-a_{1}}{a_{2}-a_{1}}, & a_{1}<x \leq a_{2}, \\
1, & a_{2}<x \leq a_{3}, \\
\frac{a_{4}-x}{a_{4}-a_{3}}, & a_{3}<x \leq a_{4}, \\
0, & x>a_{4},\end{cases} \\
& \mu(x)= \begin{cases}0, & 0 \leq x \leq a_{1}, \\
\frac{x-a_{1}}{a_{2}-a_{1}}, & a_{1}<x \leq a_{2}, \\
1, & x>a_{2},\end{cases} \\
& R=\left(r_{i j}\right)_{n \times m}=\left[\begin{array}{llll}
\mu_{11} & \mu_{12} & \cdots & \mu_{1 m} \\
\mu_{21} & \mu_{22} & \cdots & \mu_{2 m} \\
& & & \\
\mu_{n 1} & \mu_{n 2} & \cdots & \mu_{n m}
\end{array}\right] \\
& =\left[\begin{array}{lllll}
\mu_{11} & \mu_{12} & \mu_{13} & \mu_{14} & \mu_{15} \\
\mu_{21} & \mu_{22} & \mu_{23} & \mu_{24} & \mu_{25} \\
\mu_{31} & \mu_{32} & \mu_{33} & \mu_{34} & \mu_{35} \\
\mu_{41} & \mu_{42} & \mu_{43} & \mu_{44} & \mu_{45}
\end{array}\right],
\end{aligned}
$$

3.3. Determination of Index Weight. The weight is determined according to the overstandard weighting method, that is, the more the overstandard is, the greater the impact on the damage degree of roadway floor heave is and the greater the weight is, that is,

$$
W_{i}=\frac{C_{i}}{C_{0 i}},
$$

where $C_{i}$ is the actual value of $i$ index and $C_{0 i}$ is the average allowable critical value of the classification index at all levels. The weight of each index calculated by the above weight formula is a relative weight. In order to facilitate comparison, it is necessary to normalize, that is, the sum of the weight of each index is equal to 1 :

$$
\bar{W}_{i}=\frac{W_{i}}{\sum_{i=1}^{n} W_{i}}, \quad(i=1,2, \ldots, n) .
$$

The weight matrix can be obtained:

$$
A=\left(\bar{W}_{1}, \bar{W}_{2}, \ldots, \bar{W}_{i}\right)=\left(\bar{W}_{1}, \bar{W}_{2}, \bar{W}_{3}, \bar{W}_{4}\right) \text {. }
$$

3.4. Fuzzy Clustering Decision Classification. The fuzzy clustering matrix can be obtained by substituting equations (6) and (9) into (2):

$$
\mathbf{B}=A \cdot \mathbf{R}=\left(u_{1}, u_{2}, u_{3}, \ldots, u_{n}\right)=\left(u_{1}, u_{2}, u_{3}, u_{4}, u_{5}\right) .
$$

According to the principle of maximum membership, if the result vector of fuzzy comprehensive clustering matrix $B$ is $\mu_{r}$, the object belongs to class $\mathbf{R}$ :

$$
\mu_{r}=\max _{1 \leq j \leq n}\{B\} .
$$

\section{Case Analysis of Evaluation of Roadway Floor Heave Damage Degree in Zaoquan Coal Mine}

4.1. Engineering Overview of Study Site. Zaoquan coal mine is located at the edge of Maowusu Desert, $62 \mathrm{~km}$ southeast of Lingwu City, Ningxia. The administrative division is under the jurisdiction of Majiatan Township, Lingwu City. With an annual output of 8 million tons of coal, it is 


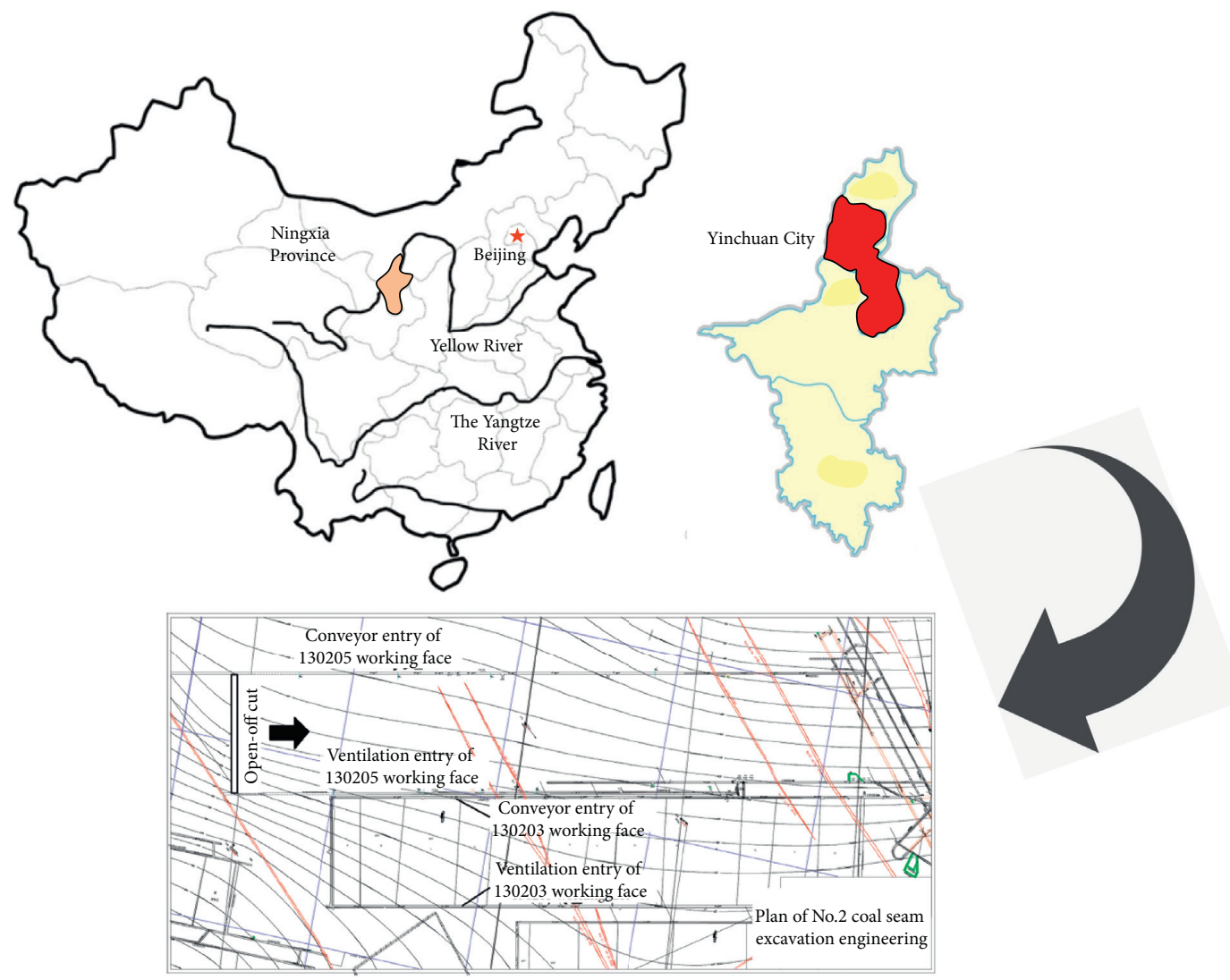

FIgURE 2: The layout of the mine location and No. 130203 working face.

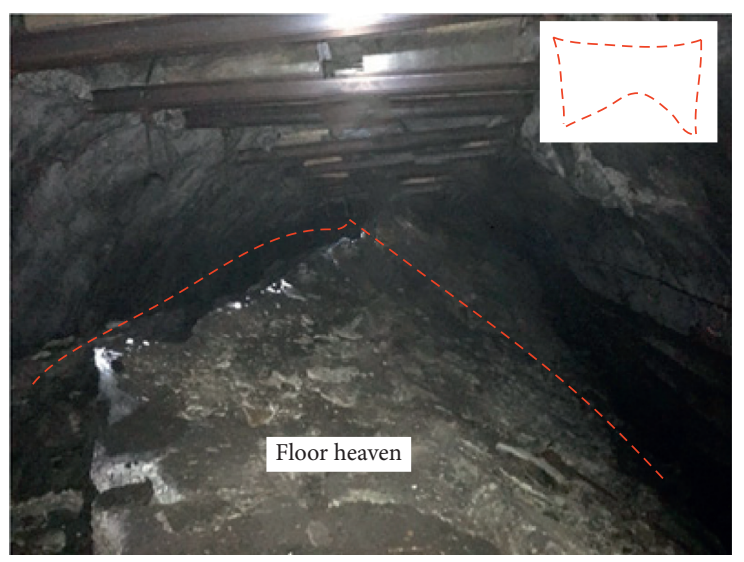

(a)

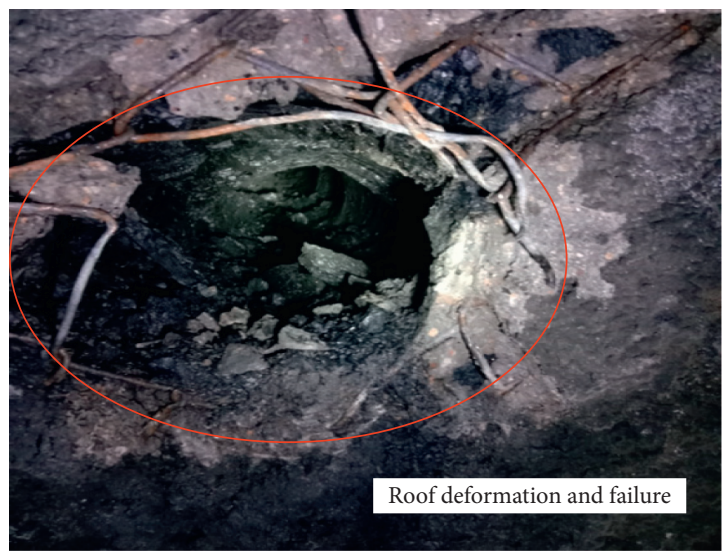

(b)

FIGURE 3: Surrounding rock deformation and failure of 130203 roadway of the Zaoquan coal mine. (a) Floor heave. (b) Roof deformation.

the main production mine of Ningmei Energy Group. Its geographical coordinates are $106^{\circ} 30^{\prime} \sim 106^{\circ} 35^{\prime} \mathrm{E}$ and $37^{\circ} 52^{\prime} \sim 38^{\circ} 02^{\prime} \mathrm{N}$. The mine field is $13 \mathrm{~km}$ long from north to south and $4 \mathrm{~km}$ wide from east to west, with an area of $52 \mathrm{~km}^{2}$. At present, 13 and 14 mining areas are under exploitation. The buried depth of the roadway has exceeded $700 \mathrm{~mm}$, and the deepest is more than $800 \mathrm{~m}$. The layout of the mine location and No. 130203 roadway is shown in Figure 2.

The No. 130203 roadway is a gob-side entry, and the roadway section is rectangular with a width of $5.1 \mathrm{~m}$ height of $3.5 \mathrm{~m}$. Because of the soft floor condition and some complex environmental factors (e.g., three highs and one disturbance) in deep mines, the floor of the No. 130203 roadway was seriously deformed, and the surrounding rock was also extensively damaged, as shown in Figure 3.

4.2. Field Detection in Zaoquan Coal Mine. Rock mechanical properties have an important influence on the floor heave. To provide the guidance and reference for the fuzzy clustering comprehensive evaluation of floor heave damage 


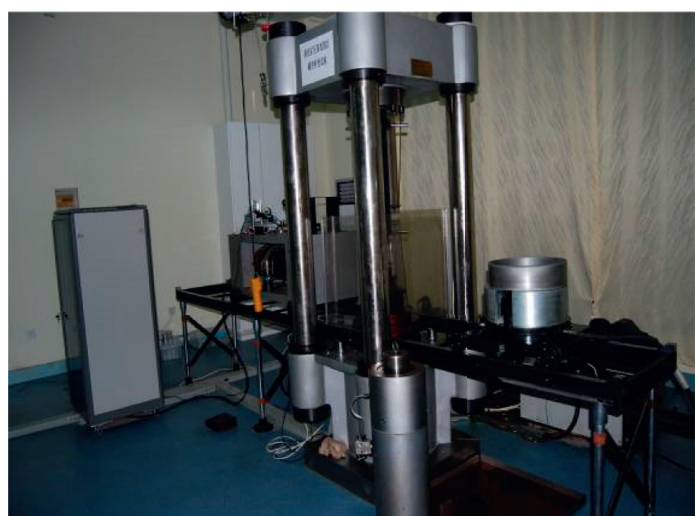

(a)

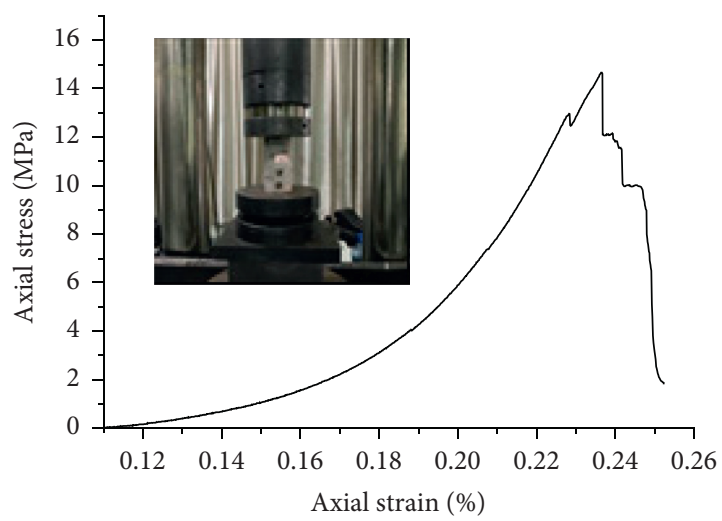

(b)

FIgURE 4: Uniaxial compression test and stress-strain curves for the rock. (a) RLJW-2000 rock mechanics testing system. (b) Axial stressstrain curves of the uniaxial compression test.

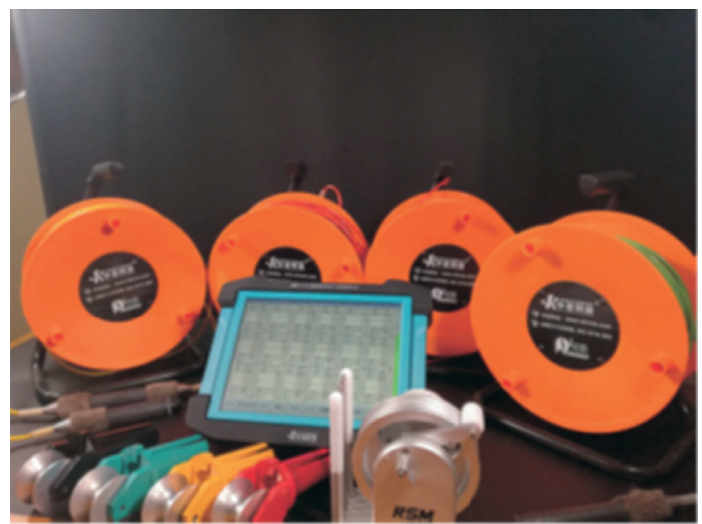

FIgURe 5: Photos of acoustic logging equipment.

degree, the mechanical properties of the surrounding rock at 130203 roadway in the Zaoquan coal mine were obtained by the uniaxial compression test on in site rock specimens. The rock specimen properties were obtained through laboratory uniaxial compression tests on rock specimens as suggested by the International Society for Rock Mechanics [32]. As shown in Figure 4(a), the rock uniaxial compression test is carried out on the RLJW-2000 testing machine, and some test curves are obtained, as shown in Figure 4(b).

Acoustic logging tool is used to detect the development of floor fractures. During monitoring, water should be injected into the borehole to ensure the transmission of sound wave. During the test, the probe of the ultrasonic instrument is placed at the bottom of the borehole. When the borehole is full of water, pull the probe outward $0.5 \mathrm{~m}$ each time to measure a little data until the orifice. The test mode of one transmitter and two receivers can be used in the test. The structure of the acoustic logging tool is shown in Figure 5.

The in situ stress measurement is carried out in the roadway roof drilling. Firstly, the middle part of the roadway roof is drilled vertically upward with a diameter of $56 \mathrm{~mm}$ and a depth of $20 \mathrm{~m}$. In the drilled hole, a pair of rubber packers is sent to the designated position of the hole by the drill pipe. Then, high-pressure water is injected to inflate the packer and seal the rock hole between the two packers. Highpressure water injection was applied to the rock holes between packers until the surrounding rock was fractured. The direction of fracturing is the direction of maximum horizontal stress.

The in situ stress measuring instrument is SYY-56 small aperture hydrofracturing in situ stress measuring device. The main technical indexes are as follows: (1) the diameter of the borehole is $56 \mathrm{~mm}$. (2) The maximum depth is $30 \mathrm{~m}$. (3) The maximum water pressure is $40 \mathrm{MPa}$. (4) The positioning accuracy is $3^{\circ}$. The in situ stress measuring device and its schematic diagram are shown in Figure 6.

\subsection{Analysis of Floor Heave Damage Degree in Zaoquan Coal} Mine. According to the above measurement results, the field measured values of each index are listed in Table 6 .

Using the fuzzy comprehensive clustering method, the damage degree of floor heave in 130203 return air roadway of the Zaoquan coal mine is classified. The membership degree of each index is calculated according to equations (3) (5), and the fuzzy relation matrix is obtained by substituting equation (6): 


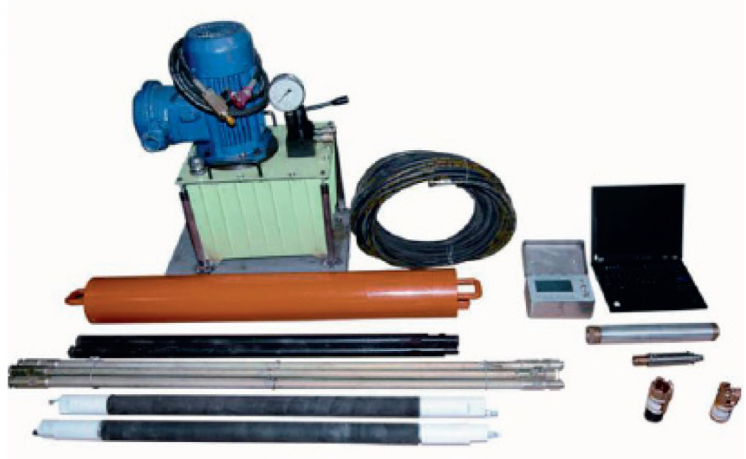

(a)

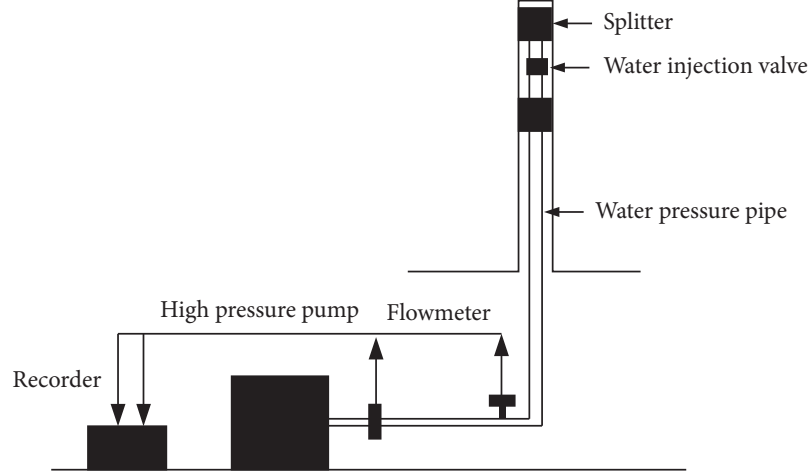

(b)

FIgURE 6: In situ stress measuring device and schematic diagram. (a)SYY-56 hydraulic fracturing ground stress measuring device. (b) Schematic diagram of in situ stress measurement by hydraulic fracturing.

TABLE 6: Measured value of floor heave damage degree of No. 130203 roadway in the Zaoquan coal mine.

\begin{tabular}{lccccc}
\hline Roadway & $D(\mathrm{~mm})$ & $V\left(\mathrm{~m} \cdot \mathrm{s}^{-1}\right)$ & $P(\mathrm{~m})$ & $R_{c}\left(\sigma_{\max }\right)$ & $R_{c}(\mathrm{MPa})$ \\
\hline No. 130203 & 732 & 2383 & 5 & 2.27 \\
\hline
\end{tabular}

TABLE 7: Weight table of the classification index for measured value of floor heave damage degree of No. 130203 roadway in the Zaoquan coal mine.

\begin{tabular}{|c|c|c|c|c|c|}
\hline \multirow{2}{*}{ Category } & \multicolumn{5}{|c|}{ Index } \\
\hline & $D(\%)$ & $V\left(\mathrm{~m} \cdot \mathrm{s}^{-1}\right)$ & $P(\mathrm{~m})$ & $R_{c}\left(\sigma_{\max }\right)$ & $R_{c}(\mathrm{MPa})$ \\
\hline Measured value $C_{i}$ & 732 & 2383 & 5 & 2.27 & 13.56 \\
\hline Critical value average $C_{0 i}$ & 480 & 4200 & 7 & 6 & 34 \\
\hline Weight value $W_{i}$ & 1.525 & 0.567 & 0.714 & 0.378 & 0.399 \\
\hline Normalized weight coefficient $\bar{W}_{i}$ & 0.43 & 0.16 & 0.20 & 0.11 & 0.11 \\
\hline
\end{tabular}

$$
R=\left[\begin{array}{ccccc}
0 & 0 & 0 & 0 & 1 \\
0.23 & 0.77 & 0 & 0 & 0 \\
0 & 0 & 0 & 0 & 1 \\
0.43 & 0.57 & 0 & 0 & 0 \\
0.14 & 0.86 & 0 & 0 & 0
\end{array}\right]
$$

Then, according to equations (7) (9), the weight of each index is calculated and normalized (Table 7), and the weighted fuzzy set is obtained:

$$
A=(0.43,0.16,0.20,0.11,0.11)
$$

According to equation (2), the fuzzy clustering matrix can be obtained:

$$
\begin{aligned}
B= & A \cdot R=(0.43,0.16,0.20,0.11,0.11) \\
& \cdot\left[\begin{array}{ccccc}
0 & 0 & 0 & 0 & 1 \\
0.23 & 0.77 & 0 & 0 & 0 \\
0 & 0 & 0 & 0 & 1 \\
0.43 & 0.57 & 0 & 0 & 0 \\
0.14 & 0.86 & 0 & 0 & 0
\end{array}\right]=(0.10,0.28,0,0,0.63) .
\end{aligned}
$$

According to the principle of maximum subordination, the floor heave damage degree of No. 130203 roadway in the Zaoquan coal mine belongs to class $\mathrm{V}$. It is the floor heave with serious damage. The evaluation method of floor heave damage degree is not only based on the floor heave amount and floor rock fragmentation degree but also considering the coal pillar size, buried depth, and floor lithology. It greatly improves the rationality and universality of evaluation and division of floor heave damage degree. It can provide more reliable guidance and reference for roadway surrounding rock support design and stability control.

\section{Conclusions}

In this paper, the fuzzy comprehensive method is used to evaluate the damage degree of roadway floor heave, and the accuracy and rationality of the discrimination method are verified by taking No. 130203 roadway in the Zaoquan coal mine as an example. The main conclusions are as follows:

(1) Through the literature investigation of domestic and foreign coal mine roadway, subway tunnel, and other underground roadway, a total of 20 coal mine roadway and 40 subway roadway were investigated, and the main index of evaluating the roadway floor 
heave damage degree was obtained. The main indicators include floor heave amount, floor rock fragmentation degree, coal pillar size, buried depth, and floor lithology.

(2) According to the evaluation index of floor heave damage degree, the floor heave damage degree can be divided into five types: light type, obvious type, serious type, damage type, and extremely serious damage type. And, the range of the main index of different floor heave damage degrees is given.

(3) The fuzzy comprehensive method is used to evaluate the floor heave damage degree of No. 130203 roadway in the Zaoquan coal mine. According to the maximum subordinate principle, the floor heave damage degree of No. 130203 roadway in the Zaoquan coal mine belongs to class $\mathrm{V}$. It is the floor heave with serious damage. The accuracy and rationality of the method are also verified by field detection.

(4) The evaluation method of floor heave damage degree is not only based on the size of floor heave and the broken degree of floor rock but also comprehensively considers the coal pillar size, buried depth, and floor rock lithology, which greatly improves the rationality and universality of evaluation and classification of floor heave damage degree. It can provide more reliable guidance and reference for roadway surrounding rock support design and stability control. However, the number of underground roadways such as the mine or subway is relatively small, and the next step is to increase the number of samples. In addition, this paper does not discuss the damage degree of complex cavern structure, geological particularity, special construction method, or operation environment. Therefore, it is suggested to refine or adjust on this basis in specific engineering application.

\section{Data Availability}

The data used to support the findings of this study are available from the corresponding author upon request.

\section{Conflicts of Interest}

The authors declare that they have no conflicts of interest.

\section{Acknowledgments}

This work was supported by the Key R\&D Program of Shandong Province (no. 2019GSF111020).

\section{References}

[1] H. Xie, Y. Zhang, Y. Chen, Q. Peng, and J. Zhu, "A case study of development and utilization of urban underground space in shenzhen and the guangdong-Hong Kong-macao greater bay area," Tunnelling and Underground Space Technology, vol. 107, Article ID 103651, 2021.
[2] Q. Wang, Y. Wang, M. C. He et al., "Experimental research and application of automatically formed roadway without advance tunneling," Tunnelling and Underground Space Technology, vol. 114, no. 3, Article ID 103999, 2021.

[3] A. Benardos, I. Athanasiadis, and N. Katsoulakos, "Modern earth sheltered constructions: a paradigm of green engineering," Tunnelling and Underground Space Technology, vol. 41, no. 1, pp. 46-52, 2014.

[4] C. J. Fan, D. Elsworth, S. Li, L. J. Zhou, Z. H. Yang, and Y. Song, "Thermo-hydro-mechanical-chemical couplings controlling $\mathrm{CH}_{4}$ production and $\mathrm{CO}_{2}$ sequestration in enhanced coalbed methane recovery," Energy, vol. 173, pp. 1054-1077, 2019.

[5] Y. X. Guo, Y. H. Zhao, S. W. Wang, G. R. Feng, Y. J. Zhang, and H. Y. Ran, "Stress-strain-acoustic responses in failure process of coal rock with different height to diameter ratios under uniaxial compression," Journal of Central South University, vol. 28, no. 6, pp. 1724-1736, 2021.

[6] J. G. Ning, J. Wang, Y. L. Tan, and Q. Xu, "Mechanical mechanism of overlying strata breaking and development of fractured zone during close-distance coal seam group mining," International Journal of Mining Science and Technology, vol. 30, no. 2, pp. 207-215, 2020.

[7] C. Zhu, M. C. He, M. Karakus, X. H. Zhang, and Z. Guo, "The collision experiment between rolling stones of different shapes and protective cushion in open-pit mines," Journal of Mountain Science, vol. 18, no. 5, pp. 1391-1403, 2021.

[8] X. S. Liu, S. L. Song, Y. L. Tan et al., "Similar simulation study on the deformation and failure of surrounding rock of a large section chamber group under dynamic loading," International Journal of Mining Science and Technology, vol. 31, pp. 495-505, 2021.

[9] Q. Ma, Y. Tan, X. Liu, Q. Gu, and X. Li, "Effect of coal thicknesses on energy evolution characteristics of roof rockcoal-floor rock sandwich composite structure and its damage constitutive model," Composites Part B: Engineering, vol. 198, no. 1, Article ID 108086, 2020.

[10] C. Zhu, M. C. He, M. Karakus, X. H. Zhang, and Z. G. Tao, "Numerical simulations of the failure process of anaclinal slope physical model and control mechanism of negative Poisson's ratio cable," Bulletin of Engineering Geology and the Environment, vol. 80, pp. 3365-3380, 2021.

[11] Q. Ma, Y. L. Tan, X. S. Liu, Z. H. Zhao, and D. Y. Fan, "Mechanical and energy characteristics of coal-rock composite sample with different height ratios: a numerical study based on particle flow code," Environmental Earth Sciences, vol. 80, no. 8, 2021.

[12] F. Wu, H. Zhang, Q. L. Zou, C. B. Li, J. Chen, and R. B. Gao, "Viscoelastic-plastic damage creep model for salt rock based on fractional derivative theory," Mechanics of Materials, vol. 150, Article ID 103600, 2020.

[13] Z. Zhao, W. Sun, S. Chen, D. Yin, and B. Chen, "Determination of critical criterion of tensile-shear failure in brazilian disc based on theoretical analysis and meso-macro numerical simulation," Computers and Geotechnics, vol. 134, no. 11, Article ID 104096, 2021.

[14] B. Li, R. Bao, Y. Wang, R. Liu, and C. Zhao, "Permeability evolution of two-dimensional fracture networks during shear under constant normal stiffness boundary conditions," Rock Mechanics and Rock Engineering, vol. 54, no. 3, pp. 1-20, 2021.

[15] N. Barton and B. Shen, "Risk of shear failure and extensional failure around over-stressed excavations in brittle rock," Journal of Rock Mechanics and Geotechnical Engineering, vol. 9, no. 2, pp. 210-225, 2017. 
[16] Z. Zhou, S. Li, L. P. Li, L. U. Wei, and S. Shi, "Attribute recognition model of surrounding rock optimized classification and its engineering application," Journal of Central South University, vol. 44, no. 4, pp. 1611-1619, 2013.

[17] C. Zhang, S. Huang, H. Zhou, G. Cui, and F. Yang, "Study on potential failure modes of surrounding rock mass based on evaluation of geostress level," Chinese Journal of Rock Mechanics and Engineering, vol. 37, no. 346, pp. 74-82, 2018.

[18] Y. Luo, "Influence of water on mechanical behavior of surrounding rock in hard-rock tunnels: an experimental simulation," Engineering Geology, vol. 277, Article ID 105816, 2020.

[19] Y. X. Li, Z. M. Zhu, and J. L. Fan, "Effect of principal stress orientation on stability of surrounding rock of tunnels," Chinese Journal of Geotechnical Engineering, vol. 36, no. 10, pp. 1908-1914, 2014.

[20] K. Zhao, Q. Wang, J. Wang, T. Suo, J. Hao, and X. Liu, "Structural plane characteristics and stability of broken surrounding rocks," China Safety Science Journal, vol. 29, no. 9, pp. 142-147, 2019.

[21] X. S. Liu, D. Y. Fan, Y. L. Tan et al., "Failure evolution and instability mechanism of surrounding rock for close-distance chambers with super-large section in deep coal mines," International Journal of Geomechanics, vol. 21, no. 5, Article ID 04021049, 2021.

[22] X. Liu, D. Fan, Y. Tan et al., "New detecting method on the connecting fractured zone above the coal face and a case study," Rock Mechanics and Rock Engineering, pp. 1-13, 2021.

[23] C. Fan, E. Elsworth, S. Li et al., "Modelling and optimization of enhanced coalbed methane recovery using $\mathrm{CO}_{2} / \mathrm{N}_{2}$ mixtures," Fuel, vol. 253, pp. 1114-1129, 2019.

[24] S. Zhu, Z. Jiang, K. Zhou, G. Peng, and C. Yang, "The characteristics of deformation and failure of coal seam floor due to mining in Xinmi coal field in China," Bulletin of Engineering Geology and the Environment, vol. 73, no. 4, pp. 1151-1163, 2014.

[25] C. J. Fan, S. Li, D. Elsworth, J. Han, and Z. H. Yang, "Experimental investigation on dynamic strength and energy dissipation characteristics of gas outburst prone coal," Energy Science \& Engineering, vol. 8, no. 4, pp. 1015-1028, 2020.

[26] R. H. Ma, Study on Mechanism and Control Technology of Floor Heave in Coal Mine Roadway, Xi'an University of Science and Technology, Xi'an, China, 2021.

[27] G. H. Zhang, Study on Construction Parameters Optimization of Large Section Tunnel Based on Cumulative Damage Effect of Surrounding Rock, Institute of Rock and Soil Mechanics, Chinese Academy of Sciences, Beijing, China, 2010.

[28] K. X. Zhang, "Determining the reasonable width of chain pillar of deep coal seams roadway driving along next goaf," Journal of China Coal Society, vol. 36, no. S1, pp. 28-35, 2011.

[29] H. D. Wang and Y. H. Cao, "Evaluation of surrounding rock stability based on improved matter-element extension model with variable weight," China Safety Science Journal, vol. 23, no. 8, pp. 1-7, 2013.

[30] Z. Wang, S. Lima, and Á. Rocha, "Fuzzy comprehensive evaluation of physical education based on high dimensional data mining," Journal of Intelligent and Fuzzy Systems, vol. 35, no. 3, pp. 1-12, 2018.

[31] H. Zhang, X. He, and H. Mitri, "Fuzzy comprehensive evaluation of virtual reality mine safety training system," Safety Science, vol. 120, pp. 341-351, 2019.

[32] C. E. Fairhurst and J. A. Hudson, "Draft ISRM suggested method for the complete stress-strain curve for intact rock in uniaxial compression," International Journal of Rock Mechanics and Mining Science \& Geomechanics Abstracts, vol. 36, no. 3, pp. 281-289, 1999. 